\title{
Future orientation and planning in forestry: a comparison of forest managers' planning horizons in Germany and the Netherlands
}

\author{
Marjanke A. Hoogstra $\cdot$ Heiner Schanz
}

Received: 6 May 2008 / Revised: 15 August 2008 / Accepted: 11 September 2008 / Published online: 7 October 2008

(C) The Author(s) 2008. This article is published with open access at Springerlink.com

\begin{abstract}
Long range (or strategic) planning is an important tool for forest management to deal with the complex and unpredictable future. However, it is the ability to make meaningful predictions about the rapidly changing future that is questioned. What appears to be particularly neglected is the question of the length of time horizons and the limits (if any) to these horizons, despite being considered one of the most critical factors in strategic planning. As the future creation of values lies within individual responsibility, this research empirically explored the limits (if any) of individual foresters' time horizons. To draw comparisons between countries with different traditions in forest management planning, data were collected through telephone surveys of forest managers in the state/national forest services of the Netherlands and Germany. In order to minimize other cultural differences, the research in Germany concentrated on the federal state of Nordrhein-Westfalen, which has considerable similarities with the Netherlands, e.g. in topography, forest types and forest functions. The results show that, in practice, 15 years appears to be the most distant horizon that foresters can
\end{abstract}

Communicated by M. Moog.

M. A. Hoogstra ( $\square)$

Forest and Nature Conservation Policy, Wageningen University, P.O. Box 47, 6700 AA Wageningen, The Netherlands e-mail: Marjanke.Hoogstra@wur.nl

H. Schanz

Institute of Forest and Environmental Policy, Environmental Markets and Marketing Section, Albert-Ludwigs-University of Freiburg,

Tennenbacher Straße 4, 79106 Freiburg, Germany

e-mail: Heiner.Schanz@ifp.uni-freiburg.de identify with. This is in sharp contrast to the time horizons spanning decades and even generations that are always said to exist in forestry. The "doctrine of the long run"- the faith in the capacity of foresters to overcome the barriers of the uncertain future and look ahead and plan for long-range goals-which in many countries still underlies traditional forest management, can therefore be rejected.

Keywords Forest management · Germany · Netherlands · Planning $\cdot$ Planning horizons $\cdot$ Time horizons

\section{Introduction}

Forest management is a long-term business. No other industrial or land-based process encounters the long time horizons underlying forestry processes, which can span decades and even generations (Zivnuska 1949, p. 166; Price 1989, p. 112; Kangas and Kangas 2005, p. 133). As a consequence, foresters have to make choices that involve outcomes that are delayed not only by weeks, months or years, but also by decades and generations (FAO 1999, p. 9). This accounts for the general assertion that a forester should be accustomed to taking the "long view", planning should be orientated on the long range.

It is therefore not surprising that (long-range) planning has traditionally occupied an important place in forestry. The scientific origins of long range forest management planning can be traced back already to seventeenth century Central Europe when, with increasing demands on wood, concerns about the wood supply for future generations came to the fore (Speidel 1972, p. 15; Convery 1973, p. 27; Duerr 1974, p. 927; Martell et al. 1998, p. 3). In the course of time, the forestry sector developed specific decisionmaking instruments to cope with the challenge of the 
future, evident in such examples as the Normal Forest model ('Normalwaldmodell') and the Faustmann formula.

Among forestry professionals the prevailing assumption about the long and uncertain future is therefore that is indeed of special importance in forestry decision-making, but that it can be handled in a fairly straightforward way: "As foresters we are accustomed to taking the 'long view'; we plant trees and designate wilderness areas with a view to servicing generations beyond our own" (Convery and Ralston 1977, p. 55). Duerr et al. (1979), p. 181 and Glück (1987), p. 159 have identified this premise of long-term thinking as a part of the "ideology of conservationism", pointing to the existence of a "doctrine of the long run" in forestry. At the heart of this doctrine, which forms one of the premises on which the strong professional ethos in forestry culture still relies (Penttinen 2007, p. 8), is a faith in the capacity of foresters to overcome the barriers of the uncertain future, and look ahead and plan for long-range goals.

Scientists have, however, questioned the ability of humans to make meaningful predictions about the far future. Boniecki (1980), p. 174 and Simons et al. (2004), p. 123, for example, state that time frames exceeding a person's life span, let alone that of his children or grandchildren, have to be questioned. They say that for most people, 20 or 30 years from now is too far away to evoke a meaningful concern leading to a concrete behavioural commitment (Boniecki 1980; Simons et al. 2004).

Similar doubts are reflected in the forestry literature. Both Stinson (1986) and Trommsdorff (1994) have highlighted that due to the extremely long time horizons in forestry, decision-makers almost never experience the outcomes of their decisions and consequently tend to think about the future as something that cannot be influenced. Convery (1973), p. 28, when describing the volatile future in forestry, sees the forester to be in a country like that described to Alice by the Red Queen in Lewis Carroll's Through the Looking Glass: "Now here, you see, it takes all the running you can do, to keep in the same place. If you want to get somewhere else, you must run at least twice as fast as that!". Others, like Duerr and Duerr (1975), p. 38, have noted that the future is often considered to be a very static one, based on the aim to keep the forest more or less similar over time (as for example in the sustained yield approach), even when growth and environmental changes might call for other approaches. It is therefore not surprising that Olson (1977), p. 42 even talks about the long range in forestry as a mirage, the nature of the illusion: "Arising from a fear of depletion-an expected future without 'planning' - the 'planned' future is a forest beyond the horizon, beyond the dazzling expanse of desert".

This presents a peculiar contradiction. One the one hand the forester is portrayed as a "visionary futurist", on the other hand there is the view on the forester as "stuck in the present" (or at least in the near future). Surprisingly, however, this debate has only scarcely been touched upon in the forestry community. That is not to say that time is not talked about; however, the discussion has mostly been limited to a description of time either as a problem or as a peculiarity.

Therefore, it is the objective of this research to empirically assess the legitimacy of the different assertions. Bringing together research from psychology, behavioural decision-making theory and strategic management, it takes an actor-oriented perspective and explores the limits (if any) to the (individual) planning horizons in forest management. The empirical analysis is based on a comparative assessment of German and Dutch foresters.

\section{Theoretical background}

There is general consensus in the literature that planning is a future oriented activity. It provides a tool for both individuals and organizations to cope with the complex and uncertain future (Noss 2002). However, this is as far as consensus reaches; already the term "future" is a highly contested and very vague concept in planning. For the purpose of this study it is sufficient to follow Cooper et al. (1999), p. 12, who simply define it as "not the past or the present", suggesting that planning means thinking forward, taking a long range perspective. A more pressing issue is the relative paucity in the literature with regard to the more fundamental question of "over what timeframe is this future?".

The subject of planning horizons, referring to the distance into the future for which to plan, is usually treated peripherally in texts on planning (Das 1991, p. 52). Many authors acknowledge the importance of the right planning horizon as a critical factor in the planning process of an organization as it forms the basis for the allocation of resources and energies, as well as the coordination of shortrun and long-range planning (e.g., Taylor and Hawkins 1972; Das 1987, p. 204). However, conclusions regarding the adequate length of planning horizons generally remain quite vague. On the one hand, it is claimed that a planning horizon should be long enough to allow organizations to reach the objectives set for this time-span. On the other hand, it is argued that too long planning horizons receive only "lip service" as nothing is permanent but change (Goodman 1973, p. 215; Boniecki 1980, p. 174).

Assessing time horizons is possible due to the fact that planning is associated with a conscious intention to engage in a type of activity that lies in the future. "Future" in planning thus always embraces anticipated activities or events (Das 1991, p. 53). This notion of "futurity" is central to the 
determination of the appropriate planning horizon (Das 1987, p. 204): the essence of planning is to make present decisions with knowledge of their futurity. And it is exactly this futurity that determines the time-span (Drucker 1972, p. 13).

However, owing no doubt to conventions and formal procedures, the futurity aspect in forest management planning has been addressed purely in quantitative and mechanistic (technical) terms following traditional conventions and planning models. The timeframes chosen depend on criteria such as the production period (rotation) of trees (Speidel 1972, pp. 95-96; Andersson 2005, p. 8), the transaction costs of formulating a plan (Speidel 1972, pp. 95-96; Friedman and Segev 1976, p. 87) and the rate of interest (Duerr 1960, p. 225; Friedman and Segev 1976, p. 87). Such a technical determination of futurity completely disregards the individual judgments of the actors in the organization of the future. All individuals unavoidably have some perspective about the future, whether it be long- or shortterm oriented (Das 1987, p. 204). The fact that an organization has fixed predilections about future time dimensions does not imply that all people in that organization are predisposed towards, for example, a 10-year or a 50-year planning horizon. On the contrary, the findings of Das (1987, 1991) and Brown and Herring (1998) clearly show that there can be significant differences ("freedom of interpretation") between the planning horizon of the organization and the individual time horizons of the actors in that organization.

In the context of this research, it is important that a negative correlation between the distance in time of a certain goal and the psychological distance towards that future goal exists. In other words, the further in time a perceived goal, the less it motivates action (Gjesme 1981, 1983; Bandura 1986; Moreas and Lens 1991; Simons et al. 2004). And when a person perceives a certain goal to be "very far away", this goal does not even influence his present actions anymore (Gjesme 1975, p. 156; Boniecki 1980, p. 174; Gjesme 1981, p. 129). How far "very far away" is, is not only situationally determined, but also depends on the individual (Gjesme 1983, p. 449). People with a long time horizon experience the (psychological) distance towards a given goal as psychologically much shorter than people with a short time horizon. For the latter, the same future goal may not even be part of their life space. Of particular importance is that, when a goal is set in the very near or in the very far future, this does not affect the psychological distance towards this goal. Tomorrow or next weekend is very near for every individual, independent of the length of the time horizons of that individual, while timeframes exceeding a person's life span, let alone that of his children or grandchildren, are unimaginable, regardless of the extension of one's time horizon (Boniecki 1980; Simons et al.
2004). For example, Boniecki (1980), p. 174 found that a time-span of 20 years appears already too distant for many individuals to evoke a meaningful concern leading to a concrete behavioural commitment. A period of $10-15$ years seems to be the most distant practical horizon for contemporary Western man. Any planning for longer than this period is likely to fail.

However, any empirical determination of time horizons is faced with a severe difficulty. As Kasakos (1971), p. 24 demonstrated, quality and meaning of time horizons can be interpreted in light of cognitive processes and reconstructed out of communication. Their direct, objective measurement, however, remains impossible. Instead, time horizons can only be assessed and compared indirectly through auxiliary constructs. One of these constructs that have been developed is the Life Space Sample (LSS) technique of Graves $(1962,1967,1974)$ and Jessor et al. (1968) who for their part were inspired by the Future Time Perspective Inventory of Wallace (1956). The LSS technique asks participants to look ahead and generate a list of a number of events (usually ten) the participants plan to do or expect to happen in the future. The participants are then asked to estimate how long from now each future event would likely occur. These data can be scored in a variety of ways, but what has proved to be the simplest and empirically most satisfactory method is to calculate the median time from the present at which these events are expected to occur. This score then becomes a summary of the "extension" of the entire sample of events (Graves 1974, p. 70). The underlying assumption is that the future for an individual exists only to the extent that he is capable of forming an image of it. Conversely, a lack of interest or involvement of the future is often interpreted as the lack of such an image. The sample of events mentioned reflects the degree to which an individual thinks and is concerned with future consequences. It gives an indication of the critical period of time in which a person is willing to take action to reach a certain goal (Jessor et al. 1968, p. 308).

The LSS technique has proven to be a valid measure of time horizons (Jessor et al. 1968; Graves 1974), and hassince its development in the 1960s and 1970s-been used in different areas of research such as substance (mis)use (Murphy and DeWolfe 1985), career perspectives (Marko and Savickas 1998), and crime and delinquency (Scheurer and Richter 2005). The criticism on this approach-that the LSS technique assumes that an individual has only one time horizon that functions for every area in his life (Kasakos 1971) — can be avoided by focusing only on one of the six areas where a certain time perspective may be maintained, namely family, personal development, work field, economics, environment, and politics (Lamm et al. 1976). In the context of this research, this means focusing on the work field of forest managers. 
It remains important from a viewpoint of triangulation to complement the LSS technique with other constructs. For this, we chose a more open approach adapted from the approach used by Boniecki (1980) in which one asks (1) whether and (if so) in what terms forest managers have thought of what their forest will be like in 20 or 30 years time and (2) if forest managers have a specific wish, goal, ambition for the future of his forest that means a lot to them and the time (from now) in which they think this could be achieved.

\section{Methodology}

\section{Research sample}

The objective of this research is to investigate the individual time horizons of forest managers and the limits (if any) to these time horizons. By "forest managers" we mean those persons that are responsible for the day-to-day management of forests. Forest managers from two different countries, namely Germany and the Netherlands, were included in the sample. The reason for choosing different countries is that several researchers have reported differences in time perspectives among countries, although the pattern and domains remained unclear (Shannon 1975; Poole and Cooney 1987; Hofstede 2001). Germany and the Netherlands were selected because in both countries foresters still form a discernible social collective within society based on their specific traditions and common objectives. However, they are contrasting cultures in regard to their forestry culture and forestry planning tradition. Germany is a classical forestry country, with a great long-standing forestry tradition and culture. It is even the cradle of traditional forest management planning (Convery 1973, p. 27; Martell et al. 1998, p. 3; Speidel 1972, p. 15). The Netherlands on the other hand, is a small forest country, lacking a strong forestry culture. Some even characterize it as a country without forest management planning; this is inaccurate, however, as the state forests have a long history of planning. Still, one cannot speak of a strong tradition in forest management planning in the Netherlands. Germany and the Netherlands are therefore excellent examples of two "polar types" in forest management planning and form excellent case studies for research into planning practices.

In any cross-cultural study, comparability of samples is both crucial and problematic (Poole and Cooney 1987, p. 133). To minimize the influence of other factors (for example topography, types of forests, forest functions), this research focused on a single federal state in Germany: North Rhine-Westphalia (NRW), which is in western Germany, bordering the Netherlands. North Rhine-
Westphalia and the Netherlands are similar in size and both have a high population density in an industrialized area, with relatively little forest cover. These similarities make it easier to identify differences in cultural background. The sampling frame used in this study further aimed at comparability along the dimensions of "organizations", i.e. forest managers working in comparable organizations, and the "function" of the managers within these organizations.

An overview of the sample characteristics is given in Table 1. The German sample comprised forest managers of the State Forest Service North Rhine-Westphalia (Landesbetrieb Forst und Holz NRW). The State Forest Service NRW consists of local forest districts (Forstamt), which are subdivided into forest management areas (Försterei or Forstbetriebsbezirk). The forests in such an area are either state-owned, privately and/or community owned, or a mix of these. Unfortunately, the after-effects of the "Kyrill" on 18 January 2007 in combination with a reorganization of the Forest Service meant it was not possible to contact all 358 forest managers. Instead, the Forest Service of North Rhine-Westphalia provided a list of 105 forest managers to be interviewed. In total, 92 were interviewed, two declined to participate and 11 could not be reached within the timeframe of the study.

The Dutch sample comprised forest and nature managers of the National Forest Service (Staatsbosbeheer). The National Forest Service consists of four regions, subdivided into districts, which in turn make up a total of 86 management units (beheereenheid). The management units of the Dutch National Forest Service consist of forest and/or nature areas, and are mostly state-owned. A list of 79 forest and nature managers to be interviewed was provided by the National Forest Service. In total, 51 managers were interviewed: five managers declined to participate, six managers did not deal with forest and nature management and were therefore not relevant for the study, four managers changed jobs during the project, and 13 could not be reached within the timeframe of the study.

The two forestry organizations have comparable planning systems: almost all (94\%) the management areas have at least one management plan, ${ }^{1}$ sometimes for 5 years, but mostly for 10 years. In some special cases (for example, in areas in National Parks) longer management plans are available. The number of plans developed for a certain

\footnotetext{
${ }^{1}$ In Germany, some privately owned areas do not have management plans. Reasons for not having a plan are that the ownership is too fragmented, that the owners do not want to have such a plan and/or that it is too costly to have this plan. The objectives for these areas are either set by the forest managers themselves, by the district office or in the form of agreements with the forest owners.
} 
Table 1 Characteristics of the sample of forest managers

\begin{tabular}{|c|c|c|c|}
\hline & Total $(N=143)$ & Germany $(n=92)$ & Netherlands $(n=51)$ \\
\hline \multicolumn{4}{|l|}{ Age (years) } \\
\hline Mean & 48.54 & 48.63 & 48.86 \\
\hline Minimum & 26 & 27 & 26 \\
\hline Maximum & 64 & 64 & 63 \\
\hline SD & 8.054 & 7.779 & 8.598 \\
\hline \multirow[t]{2}{*}{ Gender } & 134 male $(94 \%)$ & 85 male $(92 \%)$ & 49 male $(96 \%)$ \\
\hline & 9 female $(6 \%)$ & 7 female $(8 \%)$ & 2 female $(4 \%)$ \\
\hline \multicolumn{4}{|c|}{ Size of area (ha) } \\
\hline Mean & 2410.76 & 2023.14 & 3110.00 \\
\hline Minimum & 450 & 574 & 450 \\
\hline Maximum & 9,000 & 4,000 & 9,000 \\
\hline SD & 1208.77 & 693.99 & 1580.45 \\
\hline \multicolumn{4}{|c|}{ Experience as manager (years) } \\
\hline Mean & 25.39 & 25.45 & 25.29 \\
\hline Minimum & 3 & 6 & 3 \\
\hline Maximum & 49 & 47 & 49 \\
\hline SD & 10.01 & 9.66 & 10.71 \\
\hline \multicolumn{4}{|l|}{ Education } \\
\hline \multirow[t]{2}{*}{ Background } & 141 forest/nature $(99 \%)$ & 92 forestry $(100 \%)$ & 49 forest/nature $(96 \%)$ \\
\hline & 2 other $(1 \%)$ & & 2 other $(4 \%)$ \\
\hline \multirow[t]{3}{*}{ Level } & 99 college $(70 \%)$ & 92 college $(100 \%)$ & 7 college $(14 \%)$ \\
\hline & $42(\mathrm{adv})$ secondary $(29 \%)$ & & $42(\mathrm{adv})$ secondary $(82 \%)$ \\
\hline & 2 unknown $(1 \%)$ & & 2 unknown (4\%) \\
\hline
\end{tabular}

management area depends on the ownership situation of the area (Germany) or on the types of nature in the area (Netherlands). The management plans set the objectives for the area and give related guidelines; in some cases, even management actions for the specific time period are described. The longer-term plans are combined with short-term activity plans and describe the activities planned for one-year.

\section{Data collection and data analysis}

Data were collected through two identical, specially devised telephone questionnaires (one in German, one in Dutch), administered by two native speakers. The key part of the questionnaires concerned the individual time horizons. Following the LSS approach, the forest managers were asked to look ahead and generate a list of ten events they planned to do with the area they were managing. They were then asked to estimate how long from now each future event would probably happen. The specific wording of the questions ran as follows: "Please think about the future of your forest (and/or nature) area. Please list ten important management actions that you plan to carry out or would like to carry out in the future. Can you give an estimation how far into the future each action could or should occur?" In addition to the LSS task, in line with Boniecki's (1980) approach, the forest managers were asked the following questions: (1) "have you thought of what your forest would be like in 20 or 30 years' time and if so, in what terms?" and (2) "do you have a specific wish, goal, ambition for the future of your forest (and/or nature) are that is very important to you and if so, when in the future do you think this could be achieved". The questionnaires furthermore contained questions to elicit background information on the forest managers (such as gender, age, years of experience, and educational background) and the (in)formal planning practices in the respective management areas (such as the use of management plans, and departures from management plans).

The collected data was analysed with the statistical software package SPSS (version 12.0.1 for Windows). To measure the association or dependency between two variables, either the Cramer's V test (for categorical data) or the Pearson's correlation test (for continuous data) was used. Both tests indicate whether or not two variables are correlated to each other and how they are correlated. The independent $t$ test was used to measure possible different relationships between different continuous variables, and to ascertain, whether the means of the samples were different. For all tests, the conventional approach that the $P$ value must be less than 0.05 was followed. 


\section{Results}

Forest management planning

Forest management plans set out the goals and the approaches used to accomplish those goals in a given period of time; for the two organizations in this case study the period is usually 10 years. However, often priority appears to be given to shorter-term considerations.

An example of this is the use of the management plans by the forest managers. Although the majority (55\%) of the forest managers said that they use the plan regularly or even as the basis for everything they do, a large group (45\%), particularly the German foresters (51\%, compared with $34 \%$ Dutch foresters) reported that they make only limited use of the plan. Two different types of reasons were given for using the plans only marginally or not at all. The first is a cognitive one, i.e. the forester knows what to do: "it is all in my head, I know what we have to do" (male, Dutch, age group 40-54 years, forest and nature area). The secondand for this research more interesting-reason is a dynamic one. Foresters indicate that the plans are only of limited use as the day-to-day management is not always determined by the management plans, but by short-term considerations: "there are so many unexpected events, that one cannot take the course that was planned" (male, German, age group 4054 years, private/community forest) or "in practice, the management is based on the market situation and the allocation of means" (male, German, age group 55-65 years, state and private/community forest).

The influence of the short-term on planning is also reflected in the forest managers' perceptions of how often they

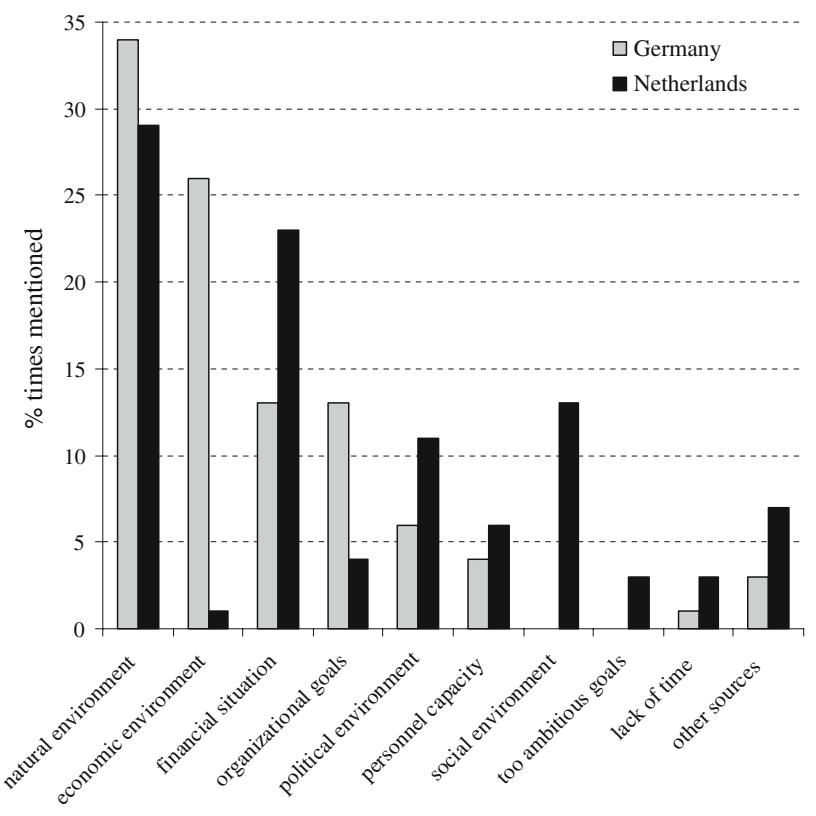

Fig. 1 Sources of departures from planning have to deviate from their planning (see Table 2). Only $4 \%$ of the managers stated that they never or very rarely have to depart from what was planned, while more than $40 \%$ reported departing regularly to frequently.

Interestingly, significant differences exist between the Dutch and the German managers: the German foresters appear to depart from the plan much more often than the Dutch foresters (Cramer's $V=0.216, P<0.05)$. It is therefore not surprising that when asked whether the perceived uncertainty in forest management is high, especially when compared to other sectors, most German managers (62\%) agreed. The Dutch managers had a different opinion (Cramer's $V=0.276, P<0.01$ ); more than $65 \%$ saw forest management as being no more uncertain than other business sectors or not uncertain at all. This difference in subjective experience between German and Dutch foresters might be explained by the fact that the Germans objectively encounter more change. It is also possible, however, that there is a cultural difference in perceptions; research has shown that compared to the Dutch, Germans feel more uncomfortable in unstructured situations, rely more on rules, laws and regulations and more actively seek to avoid the uncertainty (Hofstede 2001).

There are differences between the foresters in the two countries not only in terms of their experience of change, but also in the root causes of these departures (see Fig. 1). In both countries the natural environment is the main source triggering departures; most of the departures mentioned were responses to the weather (drought, storms, frost). However, there were differences (sometimes large) between the countries for all the other sources. For Germany, the economic environment - in particular, the timber market-was prominent. Only a few Dutch managers mentioned this as a trigger for departures; this might be because timber production plays a subordinate role in the Dutch National Forest Service. Dutch forest managers frequently mentioned the financial situation within the organization, i.e. the budget available for the management, is frequently mentioned. They usually mentioned the lack of money, but some also mentioned an unexpected surplus of money for certain projects and issues. These two factors clearly show the difference in the financial motivation of the two organizations: the State Forest Service of NRW as a business that has to generate its income primarily through the sale of timber, and the Dutch National Forest

Table 2 Forest managers' experiences of departures from forest management plans

\begin{tabular}{llll}
\hline & $\begin{array}{l}\text { Total } \\
(N=143)\end{array}$ & $\begin{array}{l}\text { Germany } \\
(n=92)\end{array}$ & $\begin{array}{l}\text { Netherlands } \\
(n=51)\end{array}$ \\
\hline Often, regularly & $62(43.4 \%)$ & $46(50.0 \%)$ & $16(31.4 \%)$ \\
Occasionally & $75(52.4 \%)$ & $41(44.6 \%)$ & $34(66.6 \%)$ \\
Seldom, never & $6(4.2 \%)$ & $5(5.4 \%)$ & $1(2.0 \%)$ \\
\hline
\end{tabular}


Service as a producer of goods and services mainly on the basis of a certain budget (provided by the Dutch Ministry of Agriculture, Nature Management and Food Quality). The specific relationship between the Dutch Ministry and the Dutch Forest Service might also account for the higher score of the political environment for the Dutch. Also of particular note is the high Dutch score for the social environment; by contrast, none of the German foresters mentioned this aspect. Especially the (lack of) public support for certain forest management actions is frequently mentioned by the Dutch foresters as a reason to depart from what is planned. This result confirms one of the characteristics of the Netherlands: the high level of societal organization, which is also found in forestry. This societal organization is reflected in the (formal and informal) involvement of a large number of various groups of stakeholders in forest management, which allows society to exert influence on forest management decisionmaking (Schanz and Ottitsch 2004).

Considering all the unexpected changes a forester faces, it is not surprising that about $50 \%$ of the foresters prefer an one-year period of management planning. One of the German foresters (male, age group 40-54 years, private/community forest area) noted "one-year is sensible, as changes happen so often" and a Dutch forester (male, age group 2539 years, forest and nature area) said "there are so many uncertainties, and the financing is also per year". Nevertheless, $35 \%$ of the forest managers prefer to make plans covering a period of more than one-year. Several managers indicated that forest management "is about the long-term; timber does not grow faster" (female, Dutch, age group 4054 years, forest and nature area) and these longer-term demands require actions to be planned for a period longer than a year. The remaining forest managers favoured a combination of the two, as the combination of the shortand the long-term is considered to be both sensible and useful. The two exceptions indicated that forest management actions should be reactive, i.e. based on what is happening at that moment: "only goals should be formulated, not forest management measures" (German male, age group 5565 years, state/private/community forest).

The results so far show that long-range planning in forest management is not so easy: the daily reality of unplanned events forces a forest manager to regularly depart from his planning. However, the findings do not say anything about the futurity of the actions taken. To investigate to what extent forest management is still oriented on the (far) future and to explore the limits (if any) of this future, we examined the managers' time horizons.

Individual time horizons

As has been pointed out above, the future for an individual exists only to the extent that this individual is capable of forming an image of it. Conversely, a lack of interest in or involvement with the future is often interpreted as the lack of such an image (Boniecki 1980, pp. 166-167). The forest managers were asked about their images of their forest or nature area in the future, and the timeframe of these images. In contrast to the time horizons of 10-15 years, which Boniecki (1980), p. 174 observed to be the most distant horizon for Western man, it was found that more than $90 \%$ of the managers have a "vision" or "image of reference" that goes beyond this "maximum". Time frames of 20-30 years seem not to be too far away; some timeframes even went beyond the 50-year timeframe. On average, the Dutch foresters have a horizon of 38 years, which is significantly less than the average horizon of 59 years for the German foresters $[t(141)=3.026, P<0.01]$. This might be a cultural difference due to the difference in tradition in forest management planning and not due to a general country difference, as Germans in general are considered to be more short-term oriented than the Dutch (Hofstede 2001). To rule out the influence of educational background (the German foresters had on average a higher level of forestry education than the Dutch foresters) and the difference in organization (as for example the Germans also manage private and community forest), we tested whether these variables were correlated with these horizons. As all German foresters had the same educational background, this variable was tested for the Dutch only; no correlation could be found (Cramer's $V=0.652, P>0.05)$. Testing the German forest managers revealed no correlation for type of ownership (Cramer's $V=0.640, P>0.05)$. No differences could be ascribed to foresters' age $(r=0.110, P>0.05)$ or years of experience of the individual foresters $(r=0.146, P>0.05)$, or to their perception of uncertainty (Cramer's $V=0.230, P>0.05$ ).

The few managers $(7 \%)$ not having this long vision of the future seem to be constrained by what Boniecki (1980), p. 167 calls the "rate of change": " 10,20 or 30 years is too far to look ahead with all the changes and uncertainties" (male, Dutch, age group 25-39 years, nature area) and "the societal and political trends dictate what happens, elections are every four years" (male, Dutch, age group 40-55 years, forest and nature area).

These results imply that most of the forest managers have a long-term view or vision of their forests that spans several decades. However, they do not indicate whether these time horizons also evoke "a meaningful concern leading to a concrete behavioral commitment" (Boniecki 1980, p. 174). It might also be that these horizons are the "nature of the illusion": "Arising from a fear of depletion-an expected future without "planning"- the "planned" future is a forest beyond the horizon, beyond the dazzling expanse of desert" (Olson 1977, p. 42).

Consequently, as a next step we focused on the "content" of foresters' future. Using the LSS technique, the forest 
managers were asked to look ahead and then to highlight ten forest management actions that they carry out or would like to carry out in or with their forest (and/or nature) area, and when. The answers indicate how far into the future a subject tends to think, or how much of the future is maintained as part of his or her current psychological "life space".

Though at first sight, the task appeared to be straightforward, it proved difficult for the foresters: over $90 \%$ were unable to complete it. The German managers found it more difficult than the Dutch managers [on average 4 actions per person, versus approx. 5.5 actions per person: $(t(141)=-4.339, P<0.01)]$. It is not clear to what extent these differences are the result of cultural differences or situational differences (e.g. the storm Kyrill which might have lead to a stronger focus on the present in the case of the German forest managers). Still, it seems that foresters in both countries find it difficult to complete the LSS. This of course has implications for the general issue of foresters' time perspectives, as the low number of answers indicates a difficulty in thinking about the future. This is in sharp contrast with the long-term thinking in forest management that is invariably mentioned in the forestry literature, but much more in line with what Boniecki (1980) has pointed out; namely that our concern is mostly present-oriented.

In addition to the surprisingly low number of answers, the answers themselves also show that when opting to carry out a certain action the distant future is considered to only a limited extent. The answers could be classified into three types:

- cyclical actions (24\%);

- goals and objectives $(36 \%)$;

- autonomous actions (40\%).

The first group (cyclical actions) demonstrates the cyclical character of forest and nature management. The foresters from both countries mentioned about the same number of actions that are, as they themselves noted, either "cyclical", "yearly" or "continuous". The Dutch foresters, however, mentioned a more varied collection of actions: almost twice as many different actions compared with the German foresters. The most popular actions mentioned by the Dutch were mowing (14\%) and infrastructural measurements $(10 \%)$; for the Germans, the most popular was tree-thinning (27\%). These types of actions, however, do not really contain a "futurity aspect" as they are based on a continuation of the past and on a present that is close to the "eternal present" (Hall 1983).

With regard to the second and third groups, the small number of answers created some measurement problems. Median time perspective scores for these two groups had to be calculated on the basis of a very limited sample of future events. Fortunately, however, there is no correlation between the number of goals and the median time perspective $(r=-0.12, P>0.05)$ and the number of actions and the median time perspective $(r=0.005, P>0.05)$, so that scores based on different sample sizes are reasonably comparable. Nevertheless, this small sample size probably resulted in greater instability in these scores than desirable and may have contributed to poorer predictive power than might otherwise have been obtained.

Although the interviewers asked for actions, some of the answers did not refer to actions but instead to goals and objectives (for example: improving the forest values, increasing social support and developing a more stable forest). Most of the answers in this second group were given by the Dutch foresters $(60 \%)$. Interestingly, for both countries the average median time perspective of these goals and objectives was around the 15-year limit $[t(101.5)=1.693$, $P>0.05]$, which Boniecki (1980), p. 174 considers to be the most distant practical horizon for Western man. No correlations could be found between the median time perspective of the goals and age $(r=-0.226, P>0.05)$, years of experience $(r=-0.048, P>0.05)$, perception of uncertainty (Cramer's $V=0.161, \quad P>0.05$ ), level of education (Cramer's $V=0.286, P>0.05$ ) or type of forest ownership (Cramer's $V=0.440, P>0.05$ ).

The third and final group of answers were the autonomous actions. In contrast to the actions from the second group, autonomous actions have a specific time perspective assigned to them. An overview of the five autonomous actions mentioned most often (grouped according to category) by the two groups is given in Table 3. Most of the answers in this group were given by German foresters $(60 \%)$, which explain the differences in numbers of actions mentioned in the two countries. On average, the average median time perspectives for both groups were about equal: around 7 and 8 years $[t(108)=1.652, P>0.05]$. Over $90 \%$ of all the actions mentioned were between 0 and 15 years. For this group too, no correlation could be found between the median time perspective and respondent's age $(r=-0.004, P>0.05)$, years of experience $(r=-0.043, P>0.05)$, perception of uncertainty (Cramer's $V=0.101, P>0.05)$, type of ownership (Cramer's $V=0.322, \quad P>0.05)$, or level of education (Cramer's $V=0.286, P>0.05)$.

In conclusion, the outcomes of the LSS show that the future time perspective of foresters is not as long as the visions or images of references seemed to indicate. The results confirm Boniecki's (1980) outcomes, namely that time horizons extend to around the 15-year mark at most; some foresters visualize a longer orientation, but most do not have a future orientation exceeding 7.5 years.

\section{Discussion and conclusions}

Given the exploratory nature of this research, the results should be interpreted with care. However, this paper has 
Table 3 Top five forest management actions mentioned by the forest managers

\begin{tabular}{lllr}
\hline Rank & Action & Amount & $\%$ \\
\hline Germany & & & \\
1 & Infrastructure & 37 & 21.5 \\
2 & Forest maintenance & 28 & 16.3 \\
3 & Forestation & 22 & 12.8 \\
4 & Thinning & 15 & 8.7 \\
5 & Enrichment plantings & 13 & 7.5 \\
Netherlands & & & \\
1 & Regrowth removal & 8 & 11.4 \\
2 & Animal grazing & 8 & 11.4 \\
3 & Mowing & 7 & 10.0 \\
4 & Timber yield & 7 & 10.0 \\
5 & Infrastructure & 6 & 8.6 \\
\hline
\end{tabular}

brought forward empirical evidence to critique an important and long-standing hypothesis in forestry, namely the "doctrine of the long run". At the heart of this doctrine, which in many countries underlies traditional forest management, is a faith in the capacity of foresters to overcome the barriers of the uncertain future and look ahead and plan for long-term goals. However, measurement of the individual time horizon of forest managers revealed that, although they have a long-term vision (or image of reference) spanning several decades, the futurity of the actions taken is much shorter. In practice, 15 years seems to be the most distant horizon that foresters can identify with. This is exactly what Boniecki (1980) found in his research on the planning horizons of the Western man. Therefore, the "doctrine of the long run" that plays an important role in the forestry culture seems certain to fall in the realm of ideological myth making.

Even though the tendency to restrict the scope of their future time horizon runs counter to the dominant ethic of forestry, this psychological tendency may actually be quite adaptive for a forester. It is also a very normal behavioral tendency for people to respond when faced with many unintelligible and intangible uncertainties such as the case in forestry (Yaffee 1997). As Boniecki (1980), pp. 168-169 observed: "Our attempt at understanding the world around us must be focused more on shorter intervals, as the periods of continuity shrink and the change, instead of being far away, appears to be waiting just 'around the comer'. Thus intellectually, we are being put off from looking too far ahead, simply because the world of 'tomorrow' will be so different from that of "today'". Some scientists have even argued that the notion of "future" itself is increasingly becoming tenuous "as it collapses into an extended present, the basis for planning, expectation and the forward movement of the self becomes difficult to sustain" (Reith 2004, p. 392). In contemporary Western societies changes happen so fast that the future is taken into the here and now. It loses its meaning, in the sense that people are unable to think about the long-term, much less plan for it (Nilsen 1999; Nowotny 1994; Reith 2004). Thinking is aimed "at the extended present, or the immediate future" and "plans [...] can be seen as no more than a short-term projection of the present into the immediate future, or, indeed as an orientation to the extended present" (Nilsen 1999: p. 175, pp. 180-181).

Considering the findings of this research-that the futurity of actions in forestry is only limited - there is of course the question of how these (relatively short) time horizons influence (the quality of) forest management. As this was not part of this research, we can only but refer to the existing (planning) literature. In the area of strategic management, for example, many empirical studies have been carried out on the impact of strategic planning on firm performance, but interestingly these studies have not produced robust findings (Ramanujam et al. 1986, p. 347): "The results of this body of research are fragmented and contradictory". One the one hand there is the opinion that the overall effect of long-range planning is very weak (Boyd 1991). Seeing further is not necessarily always the same as seeing better. Different researchers describe the game of chess as an interesting analogy. Even grandmasters and Deep Thought (the most sophisticated chess-playing computer program) do not look very far ahead while playing excellent games (Giraud 2007, p. 2; Gray and Geanakoplos 1991; Van der Heijden 2005, p. 97). Research on perceptions and strategy has, on the other hand, however, also concluded that long-range planning positively influences firm performance (Miller and Cardinal 1994), or that it is likely to be critical for effective problem solving in someif not all-instances (Maule and Hodgkinson 2003; Mezias and Starbuck 2003). A renowned example is Royal Dutch/ Shell, who-as a result of thinking far ahead-were able to move immediately and well ahead of their competitors when the oil crisis struck in 1973. This determined their position as one of the top five multinational oil companies in the following decades (Van der Heijden 2005, pp. 5-6).

In conclusion, the outcomes of this research, combined with the insights from the studies from the planning literature, cast doubt on something that has a prominent place in the forestry community, but which has also been taken somewhat for granted so far, i.e. the topic of long range forest management planning. Further empirical research is, however, still needed to get a more complete understanding of the topic. A very interesting line of research would be to study decision-making in "real" settings. An appropriate approach would for example be the observation of actions, for example, in experiments in which foresters are confronted with uncertainty and time in real (or reality-based) forest management decision-making situations. This is also consistent with the ideas of Lipshitz and Strauss (1997) and 
March (1981), who argue that research on decision-making should be carried out in naturalistic settings, as decisionmaking is characteristically driven by situation assessment. By contrast, traditional decision-making research on uncertainty and coping with uncertainty has focused on single decision events conducted under laboratory conditions (Orasanu and Connolly 1993). Single decision events, however, do not reflect complex decision-making that occurs under real world conditions. The experiments on uncertainty carried out in the military sector (see for example St John et al. (2000)) or from the aircraft industry (see for example Cohen et al. (2000)) could serve as an example of how such research could be done.

Acknowledgments The authors would like to thank the State Forest Service of North Rhine-Westphalia (Landesbetrieb Forst und Holz NRW) in Germany and the Dutch National Forest Service (Staatsbosbeheer) for their willingness to participate in the research and their help and support in the realization of the study. Special thanks to Prof. Dr. G. Oesten and the Institute of Forestry Economics of the Albert-Ludwigs-University in Freiburg for hosting the research group and their critical comments in support of the research. Many thanks go also to Dirk Steenbergen of the Forest and Nature Conservation Policy group of Wageningen University and Franz Klingler of the Institute of Forest and Environmental Policy of the University of Freiburg for carrying out the telephone interviews. Finally, we would like to thank Matt Zylstra and Joy Burroughs for the English correction.

Open Access This article is distributed under the terms of the Creative Commons Attribution Noncommercial License which permits any noncommercial use, distribution, and reproduction in any medium, provided the original author(s) and source are credited.

\section{References}

Andersson D (2005) Approaches to Integrated strategic/tactical forest planning. Umeå: Swedish University of Agricultural Sciences, Department of Forest Resource Management and Geomatics. Report 16

Bandura A (1986) Social foundations of thought and action: a socialcognitive theory. Prentice-Hall, Englewood Cliffs

Boniecki G (1980) What are the limits to man's time and space perspectives? Toward a definition of a realistic planning horizon. Technol Forecast Soc Chang 17:161-175. doi:10.1016/00401625(80)90050-5

Boyd BK (1991) Strategic planning and financial performance-a metaanalysis. J Manag Stud 28:353-374

Brown RB, Herring R (1998) The circles of time. An exploratory study in measuring temporal perceptions within organizations. J Manag Psychol 13:580-602. doi:10.1108/02683949810245009

Cohen MS, Adelman L, Thompson BB (2000) Experimental investigation of uncertainty, stakes, and time in pilot decision making. Cognitive Technologies, Inc., Arlington

Convery FJ (1973) Forestry and long range planning. Long Range Plan 6:27-28. doi:10.1016/0024-6301(73)90022-8

Convery FJ, Ralston CW (1977) Forestry and long range planning. Duke University, Durham

Cooper PJ, Brady LP, Hidalgo-Hardeman O, Hyde A, Naff KC, Ott JS et al (1999) Public administration for the twenty-first century. Harcourt Brace College Publishers, Fort Worth
Das TK (1987) Strategic planning and individual temporal orientation. Strateg Manage J 8:203-209. doi:10.1002/smj.4250080211

Das TK (1991) Time: the hidden dimension in strategic planning. Long Range Plann 24:49-57. doi:10.1016/0024-6301(91)90184-P

Drucker PF (1972) Long-range planning means risk-taking. In: Ewing DW (ed) Long Range planning for management. Harper \& Row, New York, pp 3-19

Duerr WA (1960) Fundamentals of forestry economics. McGraw-Hill Company, New York

Duerr WA (1974) Timber supply: goals, prospects, problems. Am J Agric Econ 56:927-935. doi:10.2307/1239022

Duerr WA, Duerr JB (1975) The role of faith in forest resource management. In: Ramsey F, Duerr WA (eds) Social sciences in forestry: a book of readings. W. B. Saunders Company, Philadelphia, pp 30-41

Duerr WA, Teeguarden DE, Christiansen NB (1979) Forest resource management: decision-making principles and cases. W. B. Saunders Company, Philadelphia

FAO (1999) Beyond sustainable forest management: opportunities and challenges for improving forest management in the next millennium. FAO Forestry Policy and Planning Commission, Rome

Friedman Y, Segev E (1976) Horizons for strategic planning. Long Range Plan 9:84-89. doi:10.1016/0024-6301(76)90061-3

Giraud G (2007) The limit-price dynamics — uniqueness, computability and comparative dynamics in competitive markets: documents de Travail du Centre d'Economie de la Sorbonne 2007.20. Centre National de la Recherche Scientifique, Paris

Gjesme T (1975) Slope of gradients for performance as a function of achievement motive, goal distance in time, and future time orientation. J Psychol 91:143-160

Gjesme T (1981) Is there any future in achievement motivation? Motiv Emot 5:115-138. doi:10.1007/BF00993892

Gjesme T (1983) On the concept of future time orientation: considerations of some functions and measurements' implications. Int $\mathbf{J}$ Psychol 18:443-461. doi:10.1080/00207598308247493

Glück P (1987) Social values in forestry-synopsis. Ambio 16:158160

Graves TD (1962) Time perspective and the deferred gratification pattern in a tri-ethnic community. University of Pennsylvania, Philadelphia. Ph.D. thesis

Graves TD (1967) Psychological acculturation in a tri-ethnic community. Southwest J Anthropol 23:337-350

Graves TD (1974) Urban Indian personality and the culture of poverty. Am Ethnol 1:65. doi:10.1525/ae.1974.1.1.02a00040

Gray L, Geanakoplos J (1991) When seeing further is not seeing better. Bull Santa Fe Inst 6:1-6

Goodman RA (1973) Environmental knowledge and organizational time horizon: some functions and dysfunctions. Hum Relat 26:215-226. doi:10.1177/001872677302600207

Hall E (1983) The dance of life: the other dimension of time. Doubleday, New York

Hofstede G (2001) Culture's consequences: comparing values, behaviors, institutions, and organizations across nations. Sage, Thousand Oaks

Jessor R, Graves TD, Hanson RC, Jessor SL (1968) Society, personality, and deviant behavior. A study of a tri-ethnic community. Holt, Rinehart and Winston, Inc., New York

Kangas J, Kangas A (2005) Multiple criteria decision support in forest management-the approach, methods applied, and experiences gained. For Ecol Manage 207:133-143. doi:10.1016/j.foreco.2004.10.023

Kasakos G (1971) Zeitperspektive, Planungsverhalten und Sozialisation. Überblick über internationale Forschungsergebnisse. Juventa Verlag, München

Lamm H, Schmidt RW, Trommsdorff G (1976) Sex and social class as determinants of future orientation (time perspective) in adolescents. J Pers Soc Psychol 34:317-326. doi:10.1037/0022-3514.34.3.317 
Lipshitz R, Strauss O (1997) Coping with uncertainty: a naturalistic decision-making analysis. Organ Behav Hum Decis Process 69:149-163. doi:10.1006/obhd.1997.2679

March JG (1981) Decisions in organizations and theories of choice. In: Van de Ven A, Joyce WF (eds) Perspectives on organization design and behavior. Wiley, New York, pp 205-244

Marko KW, Savickas ML (1998) Effectiveness of a career time perspective intervention. J Vocat Behav 52:106-119. doi:10.1006/ jvbe.1996.1566

Martell DL, Gunn EA, Weintraub A (1998) Forest management challenges for operational researchers. Eur J Oper Res 104:1-17. doi:10.1016/S0377-2217(97)00329-9

Maule AJ, Hodgkinson GP (2003) Re-appraising managers' perceptual errors: a behavioural decision-making perspective. $\mathrm{Br} J$ Manage 14:33-37. doi:10.1111/1467-8551.1401007

Mezias JM, Starbuck WH (2003) What do managers know, anyway? Harv Bus Rev 81:16-17

Miller CC, Cardinal LB (1994) Strategic planning and firm performance: a synthesis of more than two decades of research. Acad Manage J 37:1649-1665. doi:10.2307/256804

Moreas AM, Lens W (1991) De motivationele betekenis van het individueel toekomstperspectief, vol 1. Psychol Rep 50. KU Leuven, center for motivation and time perspective, Leuven

Murphy TJ, DeWolfe AS (1985) Future time perspective in alcoholics, process and reactive schizophrenics, and normals. Int $\mathbf{J}$ Addict 20:1815-1822

Nilsen A (1999) Where is the future? Time and space as categories in analyses of young people. Innovation 12:175-194

Noss C (2002) From strategic management to organizational time constitution: conceptual proposals for the management of organizations in a temporalized world. Conference: "dynamic time and creative inquiry in organizational change", 18-21 June 2002, Cape Ann, MA, USA

Nowotny H (1994) Time: the modern and postmodern experience. Polity Press, Cambridge

Olson SH (1977) The mirage of long-range planning. In: Convery FJ, Ralston CW (eds) Forestry and long range planning. Duke University, Durham, pp 31-44

Orasanu J, Connolly T (1993) The reinvention of decision making. In: Klein GA, Orasanu J, Calderwood R, Zsambok CE (eds) Decision making in action: models and methods. Ablex Publishing Corporation, New York, pp 3-21

Penttinen M (2007) Portfolio management and the competitiveness of forest ownership: Dissertationes Forestales 43. Finnish Society of Forest Science, Helsinki

Poole ME, Cooney G (1987) Orientations to the future: a comparison of adolescents in Australia and Singapore. J Youth Adolesc 16:129-151. doi:10.1007/BF02138916

Price C (1989) Theory and application of forest economics. Blackwell, Oxford
Ramanujam V, Ramanujam N, Camillus JC (1986) Multiobjective assessment of effectiveness of strategic planning: a discriminant analysis approach. Acad Manage J 29:347-472. doi:10.2307/ 256192

Reith G (2004) Uncertain Times. The notion of 'risk' and the development of modernity. Time Soc 13:383-402. doi:10.1177/ $0961463 \times 04045672$

Schanz H, Ottitsch A (2004) Netherlands-forest policy paragon or NFP failure? In: Humphreys D (ed) Forests for the future: national forest programmes in Europe-Country Reports from COST Action E19. Office for Official Publications of the European Communities, Luxembourg, pp 193-206

Scheurer H, Richter P (2005) Psychologische Persönlichkeitsdiagnostik: Zur Bedeutung von Persönlichkeitsfragebogen bei der Begutachtung der Schuldfähigkeit. In: Kröter H-L, Steller M (eds) Psychologische Begutachtung im Strafverfahren. Indikationen, Methoden und Qualitätsstandards. Steinkopff, Darmstadt, pp 39-60

Shannon LW (1975) Future time perspective in three cultural groups: a cultural difference or an expectancy interpretation. Dev Psychol 11:114-175. doi:10.1037/h0076120

Simons J, Vansteenkiste M, Lens W, Lacante M (2004) Placing motivation and future time perspective theory in a temporal perspective. Educ Psychol Rev 16:121-139. doi:10.1023/ B:EDPR.0000026609.94841.2f

Speidel G (1972) Planung im Forstbetrieb: Grundlagen und Methoden der Forsteinrichtung. Verlag Paul Parey, Hamburg

St John M, Callan J, Proctor S, Holste ST (2000) Tactical decisionmaking under uncertainty: experiments I and II, technical report 1821. SSC San Diego, San Diego

Stinson KG (1986) Time Preference and future time perspective: theoretical effects on forestry investments in the third World. University of Idaho

Taylor B, Hawkins KH (1972) A handbook of strategic planning. Longman, London

Trommsdorff G (1994) Zukunft als Teil individueller Handlungsorientierungen. In: Holst E, Rinderspacher JP, Schupp J (eds) Erwartungen an die Zukunft. Zeithorizonte und Wertewandel in der sozialwissenschaftlichen Diskussion. Campus Verlag, Frankfurt am Main, pp 45-76

Van der Heijden K (2005) Scenarios. The art of strategic conversation. Wiley, Chicester

Wallace M (1956) Future time perspective in schizophrenia. J Abnorm Soc Psychol 52:240-245. doi:10.1037/h0039899

Yaffee SL (1997) Why environmental policy nightmares recur. Conserv Biol 11:328-337. doi:10.1046/j.1523-1739.1997.95204.x

Zivnuska JA (1949) Commercial forestry in an unstable economy. J For 47:4-13 